\title{
Effect of oxymatrine on hypoxic-ischemic brain injury in neonatal rats
}

\author{
Chao Wei ${ }^{1}$, Shujing Zhao ${ }^{2}$, Ruiqing Diao ${ }^{2}$, Liang $\mathrm{He}^{3}$, Weizhan Wang ${ }^{4}$, Aihuan \\ $\mathbf{L i}^{4 *}$ \\ ${ }^{1}$ Department One Ward of Neurosurgery, Zhuji People's Hospital of Zhejiang Province, Zhuji People's Hospital Affiliated to \\ Shaoxing University of Arts and Sciences, Zhuji 311800, Zhejiang Province, ${ }^{2}$ Department of Neurology, Gucheng County \\ Hospital of Hebei Province, Hengshui 253800, Hebei Province, ${ }^{3}$ Department of Ophthalmology, Hengshui Second People's \\ Hospital, Hengshui 053000, Hebei Province, ${ }^{4}$ Department of Emergency Medicine, Hudson International Peace Hospital \\ affiliated to Hebei Medical University, Hengshui 053000, Hebei Province, China
}

*For correspondence: Email: tcdvb4@163.com

\begin{abstract}
Purpose: To study the influence of oxymatrine on hypoxic-ischemic brain injury (HIBI) in neonatal rats. Methods: Newborn SPF Sprague-Dawley (SD) rats were randomly assigned to 3 groups (10 rats/group): control, $\mathrm{HIBI}$ and oxymatrine groups. Neurobehavioral latency of each rat was determined after $48 \mathrm{~h}$ of treatment, and pathological changes in rat cerebral cortex were evaluated using $H \& E$ staining. Hippocampal neurons prepared from rat brain tissue were grouped and treated as per the above in vivo study. Cell survival and neuronal apoptotic changes were measured with CCK-8 and flow cytometric analysis, respectively, while protein expressions of bcl-2, mcl-1, bax, caspase-3, PI3K, $p$ PI3K, Akt, $p$-Akt, GSK3 $\beta$ and $p$-GSK3 $\beta$ were determined with Western blotting.

Results: Treatment of HIBI rats with oxymatrine significantly reduced their neurobehavioral latencies (reflex, cliff avoidance reflex, and negative reflex (latencies), but repaired HIBI-induced histological damage in rat cerebral cortex $(p<0.05)$. It also significantly enhanced the survival of rat hippocampal neurons, while reducing neuronal apoptosis $(p<0.05)$. Moreover, oxymatrine significantly upregulated $b c l-2, \quad m c l-1, p-P I 3 K, A K T, p-A K T, G S K 3 \beta$ and $p-G S K 3 \beta$ protein expressions, but $i$ significantly downregulated the protein expressions of bax and caspase-3 in cerebral cortex of HIBI rat $(p<0.05)$. Conclusion: These results indicate that oxymatrine reduces neuronal apoptosis and alleviates $H I B I$ in rats via the regulation of proteins associated with PI3KJAkt/GSK3 $\beta$ signal pathway. This finding provides a new research direction on novel botanical monomers for treating HIBI.
\end{abstract}

Keywords: Cell survival, Hypoxic-ischemic brain injury, Neurobehavioral latency, Neuronal apoptosis, Oxymatrine

\begin{abstract}
This is an Open Access article that uses a fund-ing model which does not charge readers or their institutions for access and distributed under the terms of the Creative Commons Attribution License (http://creativecommons.org/licenses/by/4.0) and the Budapest Open Access Initiative (http://www.budapestopenaccessinitiative.org/read), which permit unrestricted use, distribution, and reproduction in any medium, provided the original work is properly credited.

Tropical Journal of Pharmaceutical Research is indexed by Science Citation Index (SciSearch), Scopus, International Pharmaceutical Abstract, Chemical Abstracts, Embase, Index Copernicus, EBSCO, African Index Medicus, JournalSeek, Journal Citation Reports/Science Edition, Directory of Open Access Journals (DOAJ), African Journal Online, Bioline International, Open-J-Gate and Pharmacy Abstracts
\end{abstract}

\section{INTRODUCTION}

Hypoxic-ischemic brain injury (HIBI) or hypoxicischemic encephalopathy (HIE), refers to newborn brain damage caused by oxygen deprivation and limited cerebral blood flow (CBF). The disease is a neurological disability caused by perinatal hypoxia, and a major cause 
of death in infants [1]. Fatality caused by HIBI may get as high as $20 \%$, while survivors may develop epilepsy, cerebral palsy, developmental delay, visual and auditory impairments, and other sequelae [2]. Statistics show that $13.6 \%$ of neonates in China suffer from asphyxia, while $15.6 \%$ of them have varied degrees of disability [3]. The condition endangers the life and health of neonates in China [3]. Since there is presently no specific treatment for $\mathrm{HIBI}$, an in-depth understanding of its molecular mechanism and attendant neurological dysfunction may provide insight on possible treatment strategies for the disease.

Traditional Chinese Medicine (TCM) has shown promising potential in the treatment of asphyxia. The herbs are readily available and inexpensive, and they are relatively of low toxicity [4]. Oxymatrine is a quinolizidine alkaloid isolated from the root of Sophora alopecuroides. The compound has been reported to possess antioxidant, anti-inflammatory, antiviral, antiapoptotic, antitumor, immunomodulatory and hepatoprotective properties [5]. Although studies have shown that oxymatrine exerts a variety of effects in vitro and in animal models, the precise molecular mechanism remains largely unknown [6]. This investigation was aimed at determination of the influence of oxymatrine on $\mathrm{HIBI}$ in neonatal rats.

\section{EXPERIMENTAL}

\section{Rats}

Newborn, specific-pathogen-free SPF rats were supplied by Guangdong Medical Experimental Animal Centre. The rats were maintained at a temperature of $25{ }^{\circ} \mathrm{C}$ and $55 \%$ humidity under equal light/dark photoperiod, and allowed ad libitum access to feed and water. The study received approval from the Animal Ethical Committee of Hudson International Peace Hospital affiliated to Hebei Medical University (approval no. 2019110304), and was conducted according to "Principles of Laboratory Animal Care" (NIH publication no. 85-23, revised 1985) [7].

Three groups of rats (10 rats/group) were used: control, $\mathrm{HIBI}$ and oxymatrine groups. The HIBI was induced in the rats via standard procedures. The rats were placed in an anoxic chamber saturated with a mixture of $8 \% \mathrm{CO}_{2}$ and $92 \% \mathrm{~N}_{2}$ at $37{ }^{\circ} \mathrm{C}$ and constant speed of $4 \mathrm{~L} / \mathrm{min}$. Timing of anoxic episodes started after attainment of stable gas flow. The procedure lasted $2.5 \mathrm{~h}$. Rats in oxymatrine group were treated with oxymatrine injection (i.p.) at a single dose of $120 \mathrm{mg} / \mathrm{kg}$ bwt $2 \mathrm{~h}$ after induction, while those in control group received equivalent volume of normal saline intraperitoneally. Neurobehavioral latency of each rat was determined after $48 \mathrm{~h}$ of treatment.

\section{Neuronal cell culture}

The cortices of rats were freed from the meninges under sterile conditions, and mechanically dissociated to single-cell suspensions using flame-polished Pasteur pipettes of progressively smaller diameters. A given tissue sample was passed through a pipette 3 - 4 times and the final diameter of the pipette was approximately $0.5-1.0 \mathrm{~mm}$. The pooled, dissected cortices were put in $2-5 \mathrm{~mL}$ of DMEM containing $1 \%(w / v)$ L-glutamine at room temperature until all the tissues were dissected. The dissociation of rat cortex was done in a 15 $\mathrm{mL}$ sterile polystyrene centrifuge tube lightly coated with $5 \%(\mathrm{v} / \mathrm{v})$ heat-inactivated fetal bovine serum (FBS). Three dissociation cycles were carried out to obtain enough cell suspension. Three groups of neuronal cells were used: control, $\mathrm{HIBI}$ and oxymatrine groups. Cells in oxymatrine group were treated with $3 \mu \mathrm{g} / \mathrm{mL}$ oxymatrine. The cells were also treated with Earle's Balanced Salt Solution (EBSS) of the same volume as the original culture, and the petri dishes were incubated for $2 \mathrm{~h}$ at $37{ }^{\circ} \mathrm{C}$ in preheated anoxic chamber.

\section{Measurement of neurobehavioral latency}

Righting reflex, cliff avoidance reflex and negative geotactic reflex latencies of rats were measured $48 \mathrm{~h}$ after treatment.

\section{Reverse reflex}

Newborn rats were placed in supine position on the test bench, and the time taken by a rat to recover from the supine position was recorded.

\section{Cliff avoidance time}

Neonatal rats were placed on the test bed $1.5 \mathrm{~cm}$ away from the edge, and the time of falling from the edge was recorded.

\section{Negative geotactic reflex}

The head of each rat was placed downward in the centre of an inclined plane at $45^{\circ}$, and the time taken to turn the head upward was recorded. 
Histopathological examination of rat cerebral cortex

Hematoxylin and eosin ( $\mathrm{H}$ \& $\mathrm{E})$ staining was used to evaluate pathological changes in cerebral cortex of each rat. A part of the excised brain tissue was fixed in $10 \%$ normal saline and paraffinized. Using a microtome, 5- $\mu \mathrm{m}$ slices were generated. Then, the sections were stained with $H$ \& $E$, and observed under a light microscope. Pathological changes in rat cerebral cortex were recorded and analysed with ImageJ analysis software.

\section{Assessment of cell survival}

Neuronal cell survival was measured with CCK-8 assay. Hippocampal neurons were cultured in 96-well plates $\left(4 \times 10^{3}\right.$ cells per well; 100 $\mu \mathrm{L} /$ well) for $20 \mathrm{~min}$ at $37{ }^{\circ} \mathrm{C}$ in a $5 \% \mathrm{CO}_{2}$ atmosphere. After oxygen and glucose deprivation/reperfusion, CCK-8 was put into every well, and the mixture was cultured for $1 \mathrm{~h}$, followed by absorbance reading at $450 \mathrm{~nm}$.

\section{Apoptosis assay}

Hippocampal neurons were cultured for $24 \mathrm{~h}$. The resultant cell suspension was trypsinized with $0.25 \%$ trypsin, rinsed two times with PBS, and vortexed with $400 \mu \mathrm{L}$ binding buffer, stained using $5 \mu \mathrm{L}$ of Annexin V-FITC and PI $(10 \mu \mathrm{L})$ away from light within $15 \mathrm{~min}$. Neuronal apoptotic changes were measured flow cytometrically.

\section{Western blotting}

Rat brain tissue was homogenized in PBS and subjected to lysis with RIPA buffer mixed with anti-protease. The protein content of the lysate was measured with BCA method, followed by SDS-polyacrylamide gel electrophoresis and electro-transfer to PVDF membrane which was sealed by incubation with $5 \%$ fat-free milk solution. Thereafter, the blots were subjected to incubation for $12 \mathrm{~h}$ at $4{ }^{\circ} \mathrm{C}$ with $1: 800$ diluted $1^{\circ}$ antibodies for mcl-1, bcl-2, bax, caspase-3, PI3K, p-PI3K, Akt, p-Akt, GSK3 $\beta, p-G S K 3 \beta$ and glyceraldehyde 3-phosphate dehydrogenase
(GADPH). Then, the membrane was rinsed three times with TBS-T, followed by incubation with HRP-linked goat anti-rabbit $\lg G 2^{\circ}$ antibody for $60 \mathrm{~min}$ at laboratory temperature. Blot development was done with X-ray film, while ImageJ Launcher software was employed for Grayscale analysis. Protein levels were calculated relative to GADPH which was used as internal reference.

\section{Statistics}

Measurement data are presented as mean \pm SEM, and were statistically analyzed using SPSS (20.0). Group comparisons were done with SNK$q$ test and $X^{2}$ test. Statistical significance was assumed at $p<0.05$.

\section{RESULTS}

\section{Effect of oxymatrine on neurobehavioral latencies}

Treatment of $\mathrm{HIBI}$ rats with oxymatrine led to significant reductions in their neurobehavioral latencies (reflex, cliff avoidance reflex, and negative reflex latencies) $(p<0.05$; Table 1$)$.

\section{Effect of oxymatrine on histology of rat cerebral cortex}

The results of $\mathrm{H}$ \& $\mathrm{E}$ staining showed that the cerebral cortices of rats in control group were complete, with uniformly arranged neurons, while those of HIBI group were highly disorganized, with reduced number of neurons characterized by pyknotic nuclei. However, the number of neurons in cerebral cortices of oxymatrine group rats was significantly increased, with closely packed neurons, and the nuclear pyknotic nuclei was markedly reduced. These results are shown in Figure 1.

\section{Effect of oxymatrine on neuronal cell survival}

Oxymatrine markedly enhanced the survival of the hippocampal neurons of HIBI rats (Figure 2).

Table 1: Comparison of neurobehavioral latencies amongst rats in the groups

\begin{tabular}{lccc}
\hline Group & $\begin{array}{c}\text { Reflex latency } \\
\text { time }(\mathbf{s})\end{array}$ & $\begin{array}{c}\text { Cliff avoidance } \\
\text { reflex latency } \\
\text { time }(\mathbf{s})\end{array}$ & $\begin{array}{c}\text { Negative reflex latency } \\
\text { time (s) }\end{array}$ \\
\hline Control & $1.26 \pm 0.41$ & $4.35 \pm 1.59$ & $18.56 \pm 6.58$ \\
$H I B I$ & $12.86 \pm 3.46^{\mathrm{a}}$ & $13.46 \pm 2.41^{\mathrm{a}}$ & $56.41 \pm 5.16^{\mathrm{a}}$ \\
Oxymatrine & $4.26 \pm 1.74^{\mathrm{ab}}$ & $5.36 \pm 2.46^{\mathrm{b}}$ & $28.19 \pm 9.56^{\mathrm{ab}}$ \\
$F$ & 143.410 & 103.990 & 143.920 \\
$P$-value & $<0.001$ & $<0.001$ & $<0.001$ \\
\hline
\end{tabular}

${ }^{\mathrm{a} P}<0.05$, vs control; ${ }^{\mathrm{b}} p<0.05$, vs with $\mathrm{HIBI}$ group 


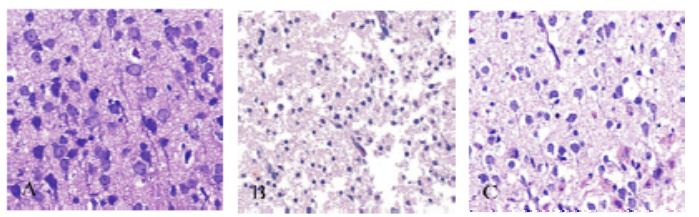

Figure 1: Comparison of pathological changes in cerebral cortices of rats. (A): H\&E staining of cerebral cortices of rats in control group; (B): Result of H\&E staining of cerebral cortices of rats in HIBI group; and (C): H\&E staining map of cerebral cortices of rats in oxymatrine group

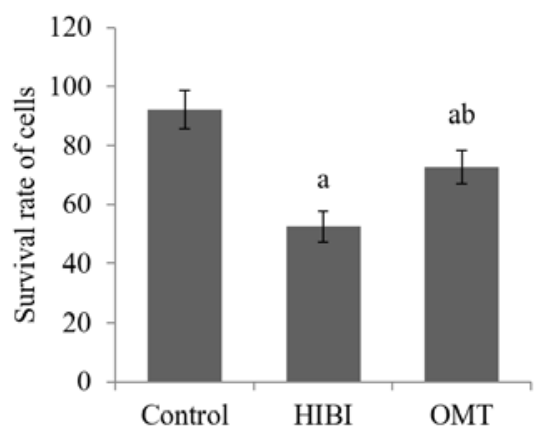

Figure 2: Comparison of cell survival among the groups. ${ }^{a} P<0.05$, vs control; ${ }^{b} p<0.05$, vs HIBI rats

\section{Neuronal apoptosis}

Neuronal apoptosis was significantly increased in HIBI rats, but it was markedly reduced by oxymatrine (Figure 3).

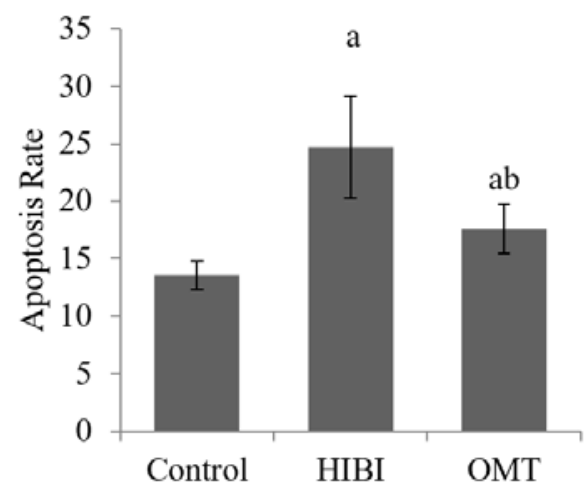

Figure 3: Comparison of neuronal apoptosis among the groups. ${ }^{a} P<0.05$, vs control; ${ }^{b} p<0.05$, vs HIBI rats

Influence of oxymatrine on levels of apoptosis-related proteins

Treatment of $\mathrm{HIBI}$ rats with oxymatrine markedly upregulated the protein expressions of bcl-2 and mcl-1, but it significantly downregulated those of caspase-3 and bax (Figure 4).

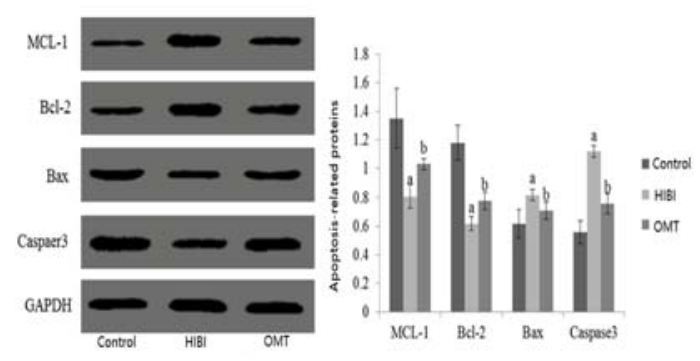

Figure 4: Comparison of expression levels of apoptosis-related proteins among the groups. (A): bcl2, mcl-1, bax and caspase-3, and (B): Quantified Western blotting results. ${ }^{a} P<0.05$, vs control; ${ }^{b} p<$ 0.05 , vs HIBI rat

\section{Levels of proteins associated with $\mathrm{PI3K/Akt/GSK3 \beta}$ signal route}

Protein expressions of $p$-PI3K, AKT, p-AKT, GSK3 $\beta$ and $p-G S K 3 \beta$ in brain tissues of HIBI rats were significantly upregulated by oxymatrine $(p<$ 0.05 ; Figure 5).

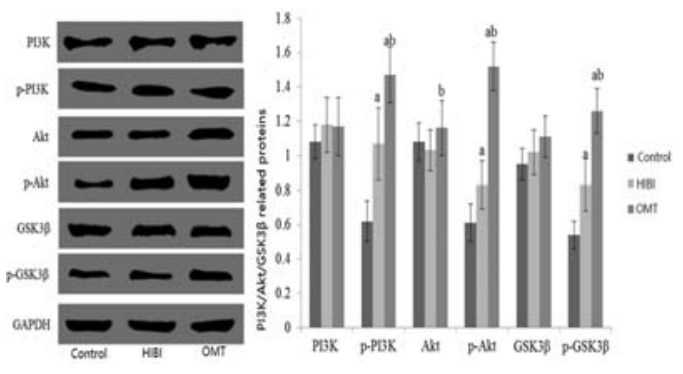

Figure 5: Levels of $\mathrm{PI} 3 \mathrm{~K} / \mathrm{Akt} / \mathrm{GSK} 3 \beta$ signal route proteins. (A): Protein expressions of PI3K, p-PI3K,

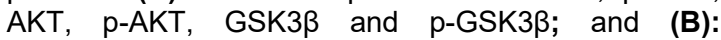
Quantified Western blotting results. ${ }^{a} P<0.05$, vs control; ${ }^{b} p<0.05$, vs HIBI. Rats

\section{DISCUSSION}

Hypoxic-ischemic brain injury ( $\mathrm{HIBI})$, also known as HIE or perinatal asphyxia, is associated with clinical and laboratory manifestation of acute or subacute brain damage. The primary causes of $\mathrm{HIBI}$ are systemic hypoxemia and reduced CBF. Asphyxia causes respiratory distress syndrome, severe haemolysis, and frequent apnoea, which in turn affect oxygen supply and metabolism in newborns. With prolonged asphyxia insult and failure of compensatory mechanisms, CBF falls, leading to ischemic brain injury. Irreversible damage to nerve cells and severe necrosis may occur in HIBI due to low tolerance of the brain tissue to ischemia and hypoxia, as well as short duration of treatment [8]. Therefore, prevention and early diagnosis are of great importance in HIBI treatment. 
Studies have shown that oxymatrine inhibited cell apoptosis and protected rabbits against arrhythmia caused by ischemia and hypoxia [9]. Oxymatrine has also been reported to alleviate myocardial ischemia in dogs [10]. This research has shown that treatment of $\mathrm{HIBI}$ rats with oxymatrine significantly reduced their neurobehavioral latencies, and also markedly reversed histological damage caused by HIBI in rat cerebral cortices. These results indicate that oxymatrine may alleviate ischemia/ hypoxiainduced neurological dysfunction, neuronal necrosis and apoptosis in neonatal rats.

The viability of neurons involves interactions amongst different signaling routes which are triggered by stress factors within cells. Changes in these signal pathways influence neuronal apoptosis or neuronal survival. In this study, treatment of $\mathrm{HIBI}$ rats with oxymatrine significantly enhanced the survival of their hippocampal neurons, while markedly reducing neuronal apoptosis. It is likely that oxymatrine inhibited neuronal apoptosis in oxygen-glucose deprivation/reperfusion (OGD/RP) injury, which is consistent with an earlier report [11].

The PI3K/Akt/GSK3 $\beta$ signaling route is crucial for maintenance of cell survival and inhibition of neuronal apoptosis during cerebral ischemia/reperfusion injury [12]. Activation of PI3K (via phosphorylation) phosphorylates and activates Akt, which in turn phosphorylates GSK3 $\beta$, thereby inhibiting its activity. Phosphorylated GSK3 $\beta$ (p-GSK3 $\beta$ ) activates downstream molecules/proteins involved in the regulation of cell proliferation, differentiation, migration and apoptosis [13]. It has been reported that activation of $\mathrm{PI} 3 \mathrm{~K} / \mathrm{Akt} / \mathrm{GSK} 3 \beta$ signaling pathway by limb ischemic preconditioning (IPC) alleviates intrauterine distress-induced brain injury, and markedly downregulates the expression of apoptosisrelated proteins in pregnant rats [14].

It is known that mcl-1 controls apoptosis and autophagy. It is a substrate for GSK3 $\beta$. Downregulation of $\mathrm{mcl}-1$ via $\mathrm{GSK} 3 \beta$ activation has been shown to contribute to $\mathrm{As}_{2} \mathrm{O}_{3}$-mediated apoptosis in acute myeloid leukemia cells. Myeloid cell leukemia-1 (mcl-1) binds to proapoptotic protein of bcl-2 family and inhibits the activation of caspases, thereby inhibiting apoptosis [15]. Up-regulation of mcl-1 has been demonstrated to potentially modulate beclin-1controlled autophagy in ischemic stroke in rats.

The proteins bcl-2 and bax are not only upstream regulators of caspase-3, but they are also direct substrates of the enzyme, thereby forming a mutually restrictive relationship [16-18]. In this study, treatment of $\mathrm{HIBI}$ rats with oxymatrine significantly upregulated protein expressions of bcl-2, mcl-1, p-PI3K, AKT, p-AKT, GSK3 $\beta$ and $p-$ GSK3 $\beta$, but significantly downregulated those of caspase- 3 and bax. These results suggest that the mechanism by which oxymatrine alleviates hypoxic ischemic injury may be linked to its regulation of proteins related to $\mathrm{PI} / 3 \mathrm{~K} / \mathrm{Akt} / \mathrm{GSK} 3 \beta$ signaling pathway.

\section{CONCLUSION}

The results obtained in this study indicate that oxymatrine reduces neuronal apoptosis and alleviates $\mathrm{HIBI}$ via regulation of $\mathrm{PI} 3 \mathrm{~K} / \mathrm{Akt} / \mathrm{GSK} 3 \beta$ signaling pathway-associated proteins. This finding provides a new research direction on novel botanical monomers for HIBI.

\section{DECLARATIONS}

\section{Conflict of interest}

No conflict of interest is associated with this work.

\section{Contribution of authors}

We declare that this work was performed by the authors named in this article and all liabilities pertaining to claims relating to the content of this article will be borne by the authors. Aihuan Li designed the study, supervised the data collection, and analyzed the data. Chao Wei interpreted the data and prepared the manuscript for publication. Shujing Zhao, Ruiqing Diao, Liang $\mathrm{He}$ and Weizhan Wang supervised the data collection, analyzed the data and reviewed a draft of the manuscript.

\section{Open Access}

This is an Open Access article that uses a funding model which does not charge readers or their institutions for access and distributed under the terms of the Creative Commons Attribution License (http://creativecommons.org/licenses/by/ 4.0) and the Budapest Open Access Initiative (http://www.budapestopenaccessinitiative.org/rea d), which permit unrestricted use, distribution, and reproduction in any medium, provided the original work is properly credited.

\section{REFERENCES}

1. Vasiljevic B. Neonatal hypoxic-ischemic brain injury. BMJ, 2017, 340(6): 561-562. 
2. Huang S, Turlova E, Li F, Bao MH, Szeto $V$, Wong $R$, Abussaud A, Wang H, Zhu S, Gao X, et al. Transient receptor potential melastatin 2 channels (TRPM2) mediate neonatal hypoxic-ischemic brain injury in mice. Exp Neurol 2017 Oct; 296: 32-40.

3. Ma $Q$, Zhang L. C-type natriuretic peptide functions as an innate neuroprotectant in neonatal hypoxic-ischemic brain injury in mouse via natriuretic peptide receptor 2 . Exp Neurol 2018; 304: 58-66.

4. Wang L, Ke J, Li Y, Ma Q, Dasgupta C, Huang X, Zhang L, Xiao D. Inhibition of miRNA-210 reverses nicotineinduced brain hypoxic-ischemic injury in neonatal rats. Int J Biol Sci 2017; 13(1): 76-84.

5. Wang L, Ke J, Li Y, Ma Q, Dasgupta C, Huang X, Zhang $L$, Xiao $D$. Inhibition of miRNA-210 reverses nicotineinduced brain hypoxic-ischemic injury in neonatal rats. Int J Biol Sci 2017; 13(1): 76-84.

6. Zhang J, Qin F, Fu L. Experimental study on reduction of myocardial injury by Sophora flavescens extract through JAK/STAT signaling pathway in rats with ischemia / reperfusion. Chin J Coal Ind Med 2019; 022(002): 177181.

7. World Health Organization. Principles of laboratory animal care. WHO Chron 1985; 39: 51-56.

8. Gao $Y, F u$, Wang J, Yang $X$, Wen L, Feng J. Resveratrol mitigates the oxidative stress mediated by hypoxic-ischemic brain injury in neonatal rats via Nrf2/HO-1 pathway. Pharm Biol 2018; 56(1): 440-449.

9. He M, Jiang L, Li B, Wang G, Wang J, Fu Y. Oxymatrine suppresses the growth and invasion of MG63 cells by up-regulating PTEN and promoting its nuclear translocation. Oncotarget 2017; 8(39): 65100-65110.

10. Ge XH, Shao L, Zhu GJ. Oxymatrine attenuates brain hypoxic-ischemic injury from apoptosis and oxidative stress: role of $p$-Akt/GSK3//HO-1/Nrf-2 signaling pathway. Metab Brain Dis 2018; 33(6): 1869-1875.

11. Qu J J, Wang S Y, Zhang C. Effect and mechanism of matrine on hemorheology in rats with focal cerebral ischemia / reperfusion. Tianjin Tradit Chin Med 2019; 36(03): 89-92.

12. Lv J, Wei $Y$, Chen $Y$, Zhang $X$, Gong Z, Jiang Y, Gong $Q$, Zhou L, Wang $H$, Xie Y. Dexmedetomidine attenuates propofol-induce neuroapoptosis partly via the activation of the PI3K/Akt/GSK3 $\beta$ pathway in the hippocampus of neonatal rats. Environ Toxicol Pharmacol 2017; 52: 121 128.

13. Zhang J, Tong $W$, Sun $H$, Jiang $M$, Shen $Y, \operatorname{Liu} Y, G u H$, Guo J, Fang J, Jin L. Nrf2-mediated neuroprotection by MANF against 6-OHDA-induced cell damage via PI3KJAKT/GSK3 $\beta$ pathway. Exp Gerontol 2017; 100: 77 86.

14. Xue M, Ji X, Xue C, Liang H, Ge Y, He X, Zhang L, Bian $K$, Zhang $L$. Caspase-dependent and caspaseindependent induction of apoptosis in breast cancer by fucoidan via the PI3KJAKT/GSK3 $\beta$ pathway in vivo and in vitro. Biomed Pharmacother 2017; 94: 898-908.

15. Zhao SJ, Kong FQ, Jie J, Li Q, Liu H, Xu AD, Yang YQ, Jiang $B$, Wang $D D$, Zhou ZQ, et al. Macrophage MSR1 promotes BMSC osteogenic differentiation and M2-like polarization by activating PI3K/AKT/GSK3 $\beta / \beta$-catenin pathway. Theranostics 2020; 10(1): 17-35.

16. Chen L, Cheng L, Wei X, Yuan Z, Wu Y, Wang S, Ren Z, Liu X, Liu H. Tetramethylpyrazine Analogue CXC195 Protects Against Dopaminergic Neuronal Apoptosis via Activation of PI3K/Akt/GSK3 $\beta$ Signaling Pathway in 6OHDA-Induced Parkinson's Disease Mice. Neurochem Res 2017; 42(4): 1141-1150.

17. Liu B, Zhao G, Jin L, Shi J. Nicotinamide Improves Cognitive Function in Mice With Chronic Cerebral Hypoperfusion. Front Neurol 2021; 12: 596641.

18. Li D, Lixia Y, Fengsui L, Haitao Z, Xinwei C. Farrerol ameliorates diabetic hepatopathy in rat model of type 2 diabetes mellitus via modulation of oxidative inflammatory stress. Trop J Pharm Res 2020; 19 (1): 71 76. 